\title{
Effect of sulfasalazine on human neuroblastoma: analysis of sepiapterin reductase (SPR) as a new therapeutic target

\author{
Lisette P. Yco ${ }^{1,2,3}$, Dirk Geerts ${ }^{4 \dagger}$, Gabor Mocz ${ }^{5 \dagger}$, Jan Koster ${ }^{6}$ and André S. Bachmann ${ }^{1,2,3^{*}}$
}

\begin{abstract}
Background: Neuroblastoma (NB) is an aggressive childhood malignancy in children up to 5 years of age. High-stage tumors frequently relapse even after aggressive multimodal treatment, and then show therapy resistance, typically resulting in patient death. New molecular-targeted compounds that effectively suppress tumor growth and prevent relapse with more efficacy are urgently needed. We and others previously showed that polyamines (PA) like spermidine and spermine are essential for NB tumorigenesis and that DFMO, an inhibitor of the key PA synthesis gene product ODC, is effective both in vitro and in vivo, securing its evaluation in NB clinical trials. To find additional compounds interfering with PA biosynthesis, we tested sulfasalazine (SSZ), an FDA-approved salicylate-based anti-inflammatory and immune-modulatory drug, recently identified to inhibit sepiapterin reductase (SPR). We earlier presented evidence for a physical interaction between ODC and SPR and we showed that RNAi-mediated knockdown of SPR expression significantly reduced native ODC enzyme activity and impeded NB cell proliferation.
\end{abstract}

Methods: Human NB mRNA expression datasets in the public domain were analyzed using the R2 platform. Cell viability, isobologram, and combination index analyses as a result of SSZ treatment with our without DFMO were carried out in NB cell cultures. Molecular protein-ligand docking was achieved using the GRAMM algorithm. Statistical analyses were performed with the Kruskal-Wallis test, 2 log Pearson test, and Student's $t$ test.

Results: In this study, we show the clinical relevance of SPR in human NB tumors. We found that high SPR expression is significantly correlated to unfavorable NB characteristics like high age at diagnosis, MYCN amplification, and high INSS stage. SSZ inhibits the growth of NB cells in vitro, presumably due to the inhibition of SPR as predicted by computational docking of SSZ into SPR. Importantly, the combination of SSZ with DFMO produces synergistic antiproliferative effects in vitro.

Conclusions: The results suggest the use of SSZ in combination with DFMO for further experiments, and possible prioritization as a novel therapy for the treatment of NB patients.

Keywords: Drug synergism DFMO, Molecular docking, Neuroblastoma, SPR, Sulfasalazine

\section{Background}

Neuroblastoma (NB) is a childhood cancer that mainly affects children up to 5 years of age [1-6]. NB is riskstratified according to patient age at diagnosis, disease stage (INSS stages 1-4 and $4 \mathrm{~s}$ ), and common genetic aberrations like MYCN oncogene amplification. This NB

\footnotetext{
* Correspondence: andre.bachmann@hc.msu.edu

${ }^{\dagger}$ Equal contributors

'Department of Pediatrics and Human Development, College of Human Medicine, Michigan State University, 301 Michigan Street, NE, Grand Rapids, MI 49503, USA

${ }^{2}$ Department of Pharmaceutical Sciences, The Daniel K. Inouye College of Pharmacy, University of Hawaii at Hilo, Hilo, HI 96720, USA

Full list of author information is available at the end of the article
}

classification is used to determine the treatment regimen, and is effective in predicting patient survival. Survival rates range from $>90 \%$ for low- to $<50 \%$ for high-risk NB [710]. Patients that suffer from high-risk NB, especially those with tumor MYCN gene amplification, show incomplete response to aggressive, multimodal therapy and often relapse and ultimately die [1-6]. While considerable progress in survival was attained by optimizing conventional interventions like chemotherapy, radiation, and bone marrow transplantation, it is now widely accepted that a therapeutic plateau has been reached. Increased treatment intensification is not considered likely to improve patient 
outcome in high-risk NB $[11,12]$. Instead, the reduction of the grave treatment complications by fine-tuning riskadapted therapy, and the development of more effectual, more specific, and less harmful molecular targeted drugs are currently viewed as the most important policies.

We and others have studied the polyamine (PA) biosynthetic pathway and its enzymes as novel targets in NB. High PA levels increase tumor cell proliferation and survival in NB and many other cancer types [13-17]. For NB, we have published that PA depletion upon addition of alpha-difluoromethylornitine (DFMO), which inhibits the key PA biosynthesis enzyme ornithine decarboxylase (ODC), readily decreases cell proliferation by activating the $\mathrm{p} 27^{\mathrm{Kip} 1} /$ retinoblastoma $(\mathrm{Rb})$ signaling axis and by inducing cell cycle arrest in the $G_{1}$ phase $[18,19]$. We also showed that $S$-adenosylmethionine decarboxylase (AdoMetDC, also known as SAMDC or AMD) is important for PA production in NB [20] and that PAs contribute to NB cell migration and metastasis [21]. In addition, we assessed the role of deoxyhypusine synthase (DHPS) that uses spermidine as a substrate for posttranslational activation/hypusination of eukaryotic initiation factor 5A (eIF5A), and found that its inhibition by $N^{1}$-guanyl-1,7-diaminoheptane (GC7) had a p21 ${ }^{\mathrm{Cip} 1} / \mathrm{Rb}$ mediated negative effect on NB cell proliferation [22].

Importantly, DFMO was also effective in vivo in both human NB tumor cell xenografts in mice and the transgenic TH-MYCN NB mouse model [23-25]. Considering its excellent safety profile and its successful use in human patients in combating trypanosomiasis (or African sleeping sickness disease), we re-targeted DFMO for NB treatment, advancing the drug through the Neuroblastoma and Medulloblastoma Translational Research Consortium (NMTRC) into multicenter phase I [26] and phase II (ongoing) clinical studies $[27,28]$.

We have previously shown that the combination of DFMO with PA uptake inhibitor AMXT-1501 was synergistic in vitro [29]. In an attempt to find additional compounds interfering with the PA biosynthesis pathway, we tested sulfasalazine (SSZ), a well-documented, FDAapproved salicylate-based anti-inflammatory and immunemodulatory drug (Fig. 1). SSZ is used to treat bowel inflammation in patients with ulcerative colitis and Crohn's disease and also indicated for use in rheumatoid arthritis. SSZ has recently been identified to inhibit sepiapterin reductase (SPR), an important enzyme in the biosynthesis of tetrahydrobiopterin (BH4) [30, 31]. BH4 is an essential cofactor in the production of serotonin, dopamine, epinephrine, norepinephrine, and nitric oxide synthase (NOS).

We earlier presented evidence for a physical interaction between ODC and SPR and we showed that RNAi-mediated knockdown of SPR expression significantly reduced native ODC enzyme activity and impeded

\section{Sulfasalazine (SSZ)}

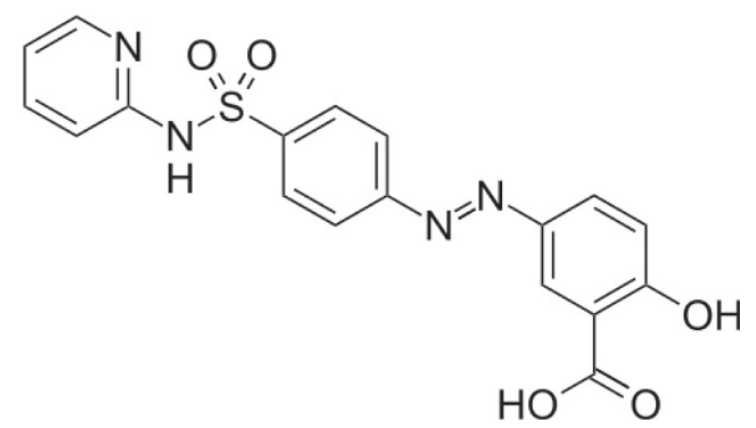

Fig. 1 Structure of Sulfasalazine (SSZ). SSZ is an amino-salicylate, specifically 5-((4- (2- Pyridylsulfamoyl) phenyl)azo) salicylic acid (systemic name: 2-hydroxy-5-[(E)-2-\{4-[(pyridin-2-yl)sulfamoyl] phenyl\}diazen-1-yl]benzoic acid), with a molecular mass of $398.394 \mathrm{~g} / \mathrm{mol}$. SSZ was developed in the 1950's to treat rheumatoid arthritis and is also indicated for the use in ulcerative cholitis and Crohn's disease. SSZ is commercially distributed under the brand names Azulfidine, Salazopyrin and Sulazine

the proliferation of NB cells, demonstrating the biological relevance of this novel interaction [32]. This current study is the first report on the cellular effects of SSZ on NB tumor cells, presumably due to the inhibition of SPR as predicted by computational docking of SSZ into SPR. We further demonstrate the clinical relevance of SPR in human NB tumors and show that the combination of SSZ with DFMO produces synergistic antiproliferative effects, suggesting the use of SSZ/DFMO combination therapies in NB patients.

\section{Results}

\section{SPR mRNA expression in NB}

We have previously reported on the role of SPR in NB proliferation [32], where we demonstrated a deleterious effect of RNAi-mediated SPR expression knockdown in the MYCN2 NB cell line. We also showed that high SPR mRNA expression was correlated to poor patient prognosis in Kaplan-Meier analysis in the Versteeg-88 NB dataset in the public domain. We now present SPR mRNA expression analysis on all $12 \mathrm{NB}$ cohorts in the public domain (Table 1). We find that high SPR expression is significantly correlated in all four NB cohorts annotated for patient survival and/or prognosis. While in our previous study [32] we could only show a trend for a correlation between SPR expression and tumor MYCN gene amplification in the Versteeg-88 set $(P=0.06)$, we can now state that SPR expression is significantly higher in patients with tumor MYCN gene amplification in 6 of 8 datasets with MYCN amplification annotation. Considering the different compositions of these datasets with 
Table 1 SPR mRNA correlations in public NB mRNA expression datasets

\begin{tabular}{|c|c|c|c|c|c|}
\hline \multirow{2}{*}{$\begin{array}{l}\text { Dataset } \\
\text { Name }\end{array}$} & \multirow[b]{2}{*}{ Samples } & \multicolumn{2}{|c|}{$\begin{array}{l}\text { SPR mRNA expression } \\
\text { correlations }\end{array}$} & \multicolumn{2}{|c|}{ Micro-array data } \\
\hline & & $\begin{array}{l}\text { Survival/ } \\
\text { prognosis }\end{array}$ & $\begin{array}{l}\text { MYCN } \\
\text { amplification }\end{array}$ & Array Type & GSE \\
\hline Delattre & 64 & n.d. & $\begin{array}{l}\text { positive } \\
\left(6.8 \cdot 10^{-6}\right)\end{array}$ & $\begin{array}{l}\text { Affymetrix } \\
\text { HG-U133 } \\
\text { Plus } 2.0\end{array}$ & 12460 \\
\hline Hiyama & 51 & $\begin{array}{l}\text { negative } \\
(0.02)\end{array}$ & $\begin{array}{l}\text { positive } \\
\left(2.8 \cdot 10^{-3}\right)\end{array}$ & $\begin{array}{l}\text { Affymetrix } \\
\text { HG-U133 } \\
\text { Plus } 2.0\end{array}$ & 16237 \\
\hline Jagannathan & 100 & $\begin{array}{l}\text { negative } \\
(0.02)\end{array}$ & $\begin{array}{l}\text { positive } \\
\left(1.7 \cdot 10^{-3}\right)\end{array}$ & $\begin{array}{l}\text { Illumina } \\
\text { Human } \\
\text { WG 6V2 }\end{array}$ & 19274 \\
\hline Kocak & 649 & n.d. & $\begin{array}{l}\text { positive } \\
\left(7.9 \cdot 10^{-15}\right)\end{array}$ & $\begin{array}{l}\text { Agilent } \\
\text { Human } \\
44 \mathrm{~K} \text { Oligo }\end{array}$ & 45547 \\
\hline Łastowska & 30 & n.d. & $\begin{array}{l}\text { positive } \\
\left(2.6 \cdot 10^{-4}\right)\end{array}$ & $\begin{array}{l}\text { Affymetrix } \\
\text { HG-U133 } \\
\text { Plus } 2.0\end{array}$ & 13136 \\
\hline Maris & 101 & n.d. & n.s. & $\begin{array}{l}\text { Affymetrix } \\
\text { HG-U95A }\end{array}$ & 3960 \\
\hline Seeger & 117 & $\begin{array}{l}\text { negative } \\
\left(1.4 \cdot 10^{-4}\right)\end{array}$ & n.d. & $\begin{array}{l}\text { Affymetrix } \\
\text { HG-U133A }\end{array}$ & 3446 \\
\hline Versteeg & 88 & $\begin{array}{l}\text { negative } \\
(0.02)\end{array}$ & n.s. & $\begin{array}{l}\text { Affymetrix } \\
\text { HG-U133 } \\
\text { Plus } 2.0\end{array}$ & 16476 \\
\hline Zhang & 498 & $\begin{array}{l}\text { negative (2.1 } \\
\left.\cdot 10^{-6}\right)\end{array}$ & $\begin{array}{l}\text { positive } \\
\left(4.6 \cdot 10^{-4}\right)\end{array}$ & $\begin{array}{l}\text { Agilent } \\
\text { Human } \\
44 \mathrm{~K} \text { Oligo }\end{array}$ & 49710 \\
\hline
\end{tabular}

Legend: The Albino-28 (GSE7529), Khan-47 (GSE27608), and Seeger-102 (GSE3446) do not contain sufficient clinical data and were not analyzed. Data were analyzed as described in the Materials and Methods. The first two columns represent name and sample size of the dataset. The two central columns show the results of SPR mRNA expression correlation analyses: with survival and/or prognosis, and with MYCN amplification. Negative or positive in the two central columns means that SPR mRNA expression correlates negative or positive with survival/good prognosis and MYCN amplification, respectively (outcomes of Kruskal-Wallis correlation tests, the number in parentheses is the $P$ value, n.s. means not significant, n.d. means not determined (data not present in the dataset)). Kocak-649 and Zhang-498 contain some common samples. The last two columns list Array type and GEO GSE number on the NCBI GEO website where full data are available

respect to patient age, MYCN amplification, and INSS stage, together with the different array platforms used for the generation of these data, this is a very robust finding. In Fig. 2, we show the results for the largest NB cohort in the public domain, the Kocak-649 dataset. Although this dataset does not contain survival data, the correlations between SPR expression and three important clinical NB parameters are highly significant (Fig. 2, a-c): age at diagnosis $(P=1.9$. $10^{-23}$, MYCN tumor amplification $\left(P=7.9 \cdot 10^{-15}\right.$, and INSS stage (various $P$ values $<0.05$ ). In addition, the Kocak-649 dataset shows a significant correlation between SPR and ODC mRNA expression (Fig. $3, \mathrm{R}=0.225, P=6.5 \cdot 10^{-9}$ ). This association, although highly significant, has a relatively low $\mathrm{R}$ value. However, since we previously found a similar association $\left(\mathrm{R}=0.289, P=6.2 \cdot 10^{-3}\right)$ in the Versteeg-88 cohort [32], we felt strengthened in our argument that this correlation is meaningful.

These results show that SPR mRNA expression is highest in all NB clinical groups with poor outcome: high age at diagnosis, tumors with MYCN oncogene amplification, and patients with high INSS tumor stage. Its expression pattern therefore resembles that of ODC, and indeed we found a tentative correlation between SPR and ODC expression. Together, these results prompted us to investigate the specific targeting of SPR alone or together with targeting of ODC as novel NB therapy.

\section{The effect of Sulfasalazine (SSZ) treatment on NB cell proliferation and survival}

A recent study by Chidley et al. revealed that SSZ blocks BH4 biosynthesis through inhibition of SPR [30]. To examine the inhibitory effects of SSZ in NB cells, we treated SK-N-Be(2)c, SK-N-SH, and LAN-5 cells with increasing concentrations of SSZ $(0-400 \mu \mathrm{M})$ and measured cell viability $48 \mathrm{~h}$ after treatment. As shown in Fig. 4, SSZ decreased the cell viability of all three NB cell lines in a dose-dependent manner. We did not observe overt apoptosis (data not shown), suggesting that SSZ inhibits cell proliferation of NB cells without cytotoxic effects.

To investigate potential signaling molecules and pathways involved in SSZ-mediated cell death, we tested the expression levels of several proteins that regulate cell proliferation, including $\mathrm{p} 27^{\mathrm{Kip} 1}$, retinoblastoma tumor suppressor protein $\mathrm{Rb}, \mathrm{Akt} / \mathrm{PKB}$, and $\mathrm{p} 44 / 42$ MAPK (Erk1/2). Western blot analysis did not reveal any significant protein expression differences between SSZ-treated and untreated NB cells (data not shown), suggesting that additional, alternative signaling pathways are activated by SSZ.

\section{Computational modeling and docking of SSZ into SPR}

To examine if SPR binds SSZ, we performed computational docking simulations. SSZ is an amino-salicylate, specifically 5-((4- (2- Pyridylsulfamoyl) phenyl)azo) salicylic acid (Fig. 1). SSZ has one canonical conformer with an MMFF94-minimized (Merck Molecular Force Field) energy of $83.9 \mathrm{kcal} / \mathrm{mol}$, which was used in the docking simulations [33]. Under physiological conditions the molecule carries a negative charge which may have a role in the interaction with the receptor.

The human SPR crystal structure is available in complex with NADP+ in a hexameric assembly (unpublished data, PDB: 1Z6Z). This biologically active, functional form of SPR exists as a dimer and has 2 -fold $\left(180^{\circ}\right)$ rotational symmetry. The SPR monomer is an alpha and beta $(\mathrm{a} / \mathrm{b})$ class protein with a 3-layer (aba) sandwich architecture and Rossmann fold topology, and it contains an NADP- binding Rossmann-like domain [34]. 


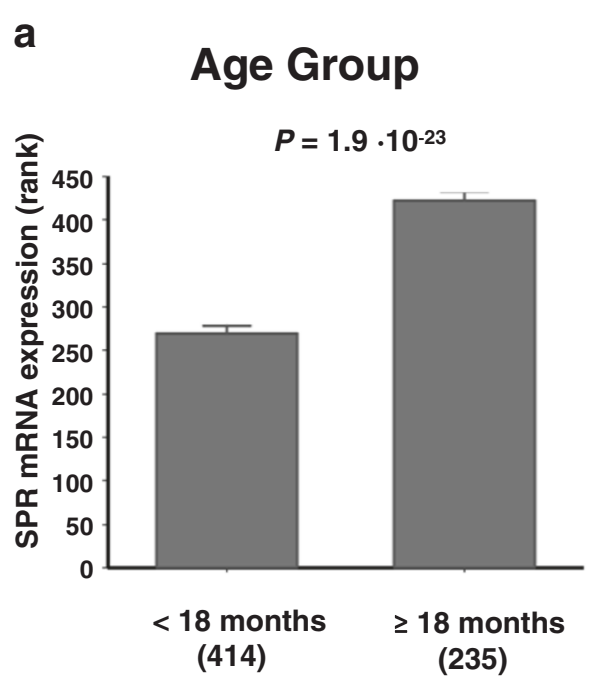

C

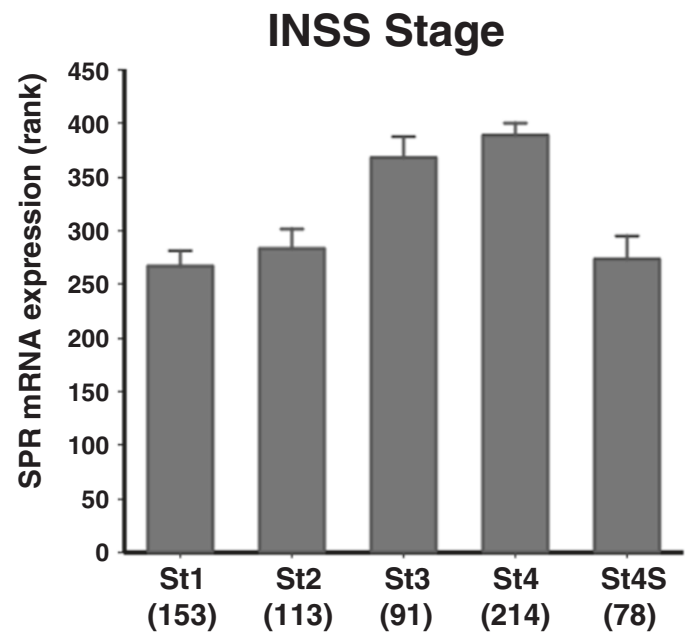

b

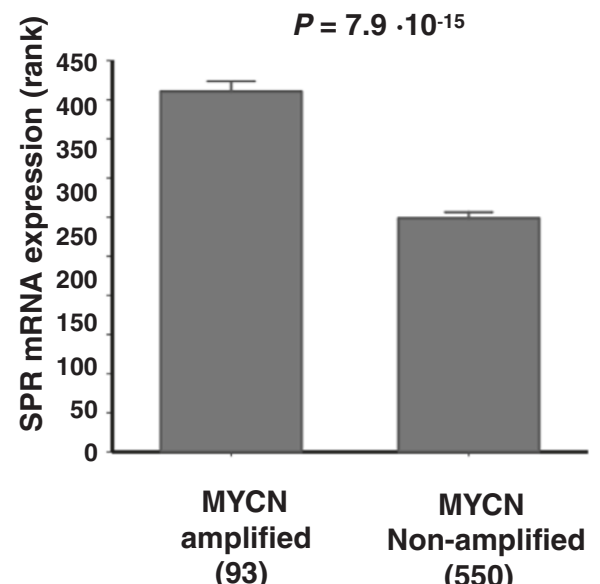

(93) (550)
St1 vs. St3 $P=3.2 \cdot 10^{-5}$
St1 vs. St4 $P=7.1 \cdot 10^{-11}$
St2 vs. St3 $P=1.8 \cdot 10^{-3}$
St2 vs. St $4 \quad P=5.0 \cdot 10^{-7}$
St3 vs. St4S $P=1.4 \cdot 10^{-3}$
St4 vs. St4S $P=1.0 \cdot 10^{-6}$

Fig. 2 SPR mRNA expression correlation with NB clinical parameters. Differential expression of SPR mRNA expression in the Kocak-649 cohort upon separation of patient samples into clinically important groups. (a) SPR expression is significantly higher in older than in younger patients (age at diagnosis $\geq 18$ months versus $<18$ months; $P=1.9 \cdot 10^{-23}$ ), (b) SPR expression is significantly higher in patients with than in patients without tumor MYCN gene amplification $\left(P=7.9 \cdot 10^{-15}\right)$, and (c) SPR expression is significantly higher in high than in low stage tumors (INSS stage 3 and 4 versus stage 1, 2, and 4S; various $P<0.05$ ). For all three parameters, SPR expression is highest in the poor outcome group. Statistical analysis was performed using the non-parametric Kruskal-Wallis tests

We explored feasible binding modes both for the SPR monomer and the dimer. The docking computations were carried out on each binding mode by geometric complementarity and semi-flexible docking to allow for inherent receptor flexibility. From each computation, the 50 lowest energy-docking positions were saved for further analysis. The presumed SSZbinding sites were ranked by conservation score, specifically by the frequency of occurrence of a residue in a contact surface. The contact surface was delimited as an area consisting of the residues inside a $3.6 \AA$ radius of the ligand.
Based on the conservation scores of all the residues, we identified the main binding location within the NADPbinding Rossmann-like domain. A consensus of five binding regions constituted the receptor pocket comprising residues Gly11, Ser13, Arg14, Phe16 (Region 1), Ala38, Arg39 (Region 2), Asn97, Ala98, Gly99, Ser100 (Region 3), Tyr167 (Region 4), and Leu198, Thr200, Met202 (Region 5). Thus, the binding pocket appeared to contain 2 basic polar residues, 5 neutral polar residues, and 7 neutral non-polar residues. Due to the presence of 2 arginine residues, the site has a basic, positively charged character which may be essential for SSZ binding. Most or all of 


\section{SPR-ODC1 mRNA expression correlation}

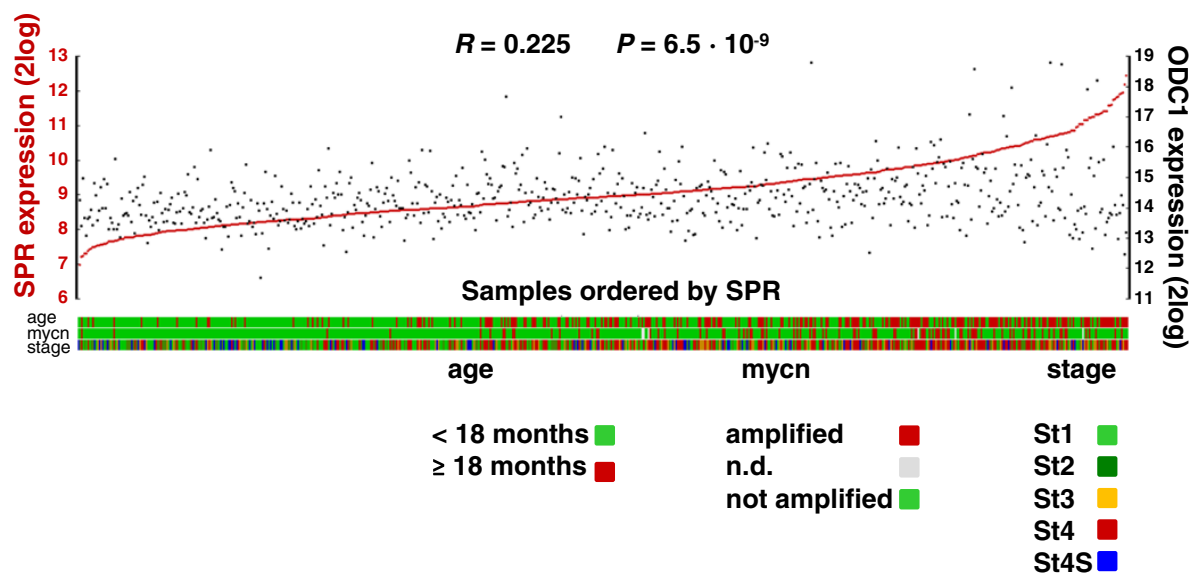

Fig. 3 SPR expression correlation with ODC expression in NB. SPR and ODC mRNA expression correlation in the Kocak-649 NB cohort: visual representation of SPR and ODC expression in all 649 NB tumor samples, ranked horizontally from left to right according to their SPR expression. SPR and ODC (2log) expression values for each sample are visualized with red circles and black rectangles, respectively. The correlation between SPR and ODC expression is $r=0.225$, with a $P$ value of $6.5 \cdot 10^{-9}$ (2log Pearson). Symbols representing the clinical values of the tumor samples: age at diagnosis, MYCN amplification, and INSS stage, are listed below the graph, together with their legend

SSZ exists in a non-protonated, negatively charged state at neutral $\mathrm{pH}$, as the acidic $\mathrm{pK}_{\mathrm{a}}$ of carboxylic acid is 2.3 and the $\mathrm{pK}_{\mathrm{a}}$ of the sulfonamide nitrogen is 6.5 , i.e. less than half-protonated at $\mathrm{pH} 7.0$ [35].

The same residues listed above are involved in NADP+ binding, but the complete NADP+ binding site extends beyond these residues (Table 2). The monomeric or dimeric state of SPR did not affect the location of the SSZ binding site in the simulations, indicating that dimerization does

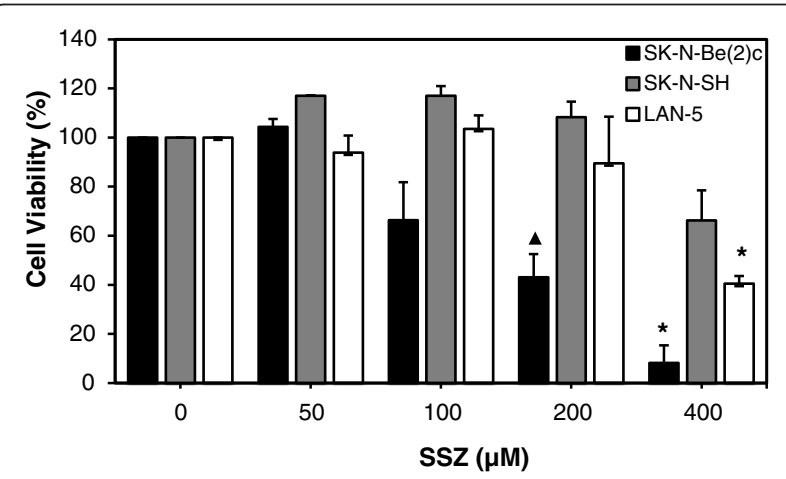

Fig. 4 Effect of Sulfasalazine (SSZ) on the viability of NB cells using the MTS cell viability assay. NB cell lines SK-N-Be(2)c, SK-N-SH, and LAN-5 were treated with increasing concentrations of SSZ for 48 hours. Dose-dependent inhibition of cell viability was observed. Statistically significant differences between values obtained from DMSO-treated control cells and SSZ-treated cells are indicated with an asterisk $\left({ }^{*} P<0.05\right)$ or solid triangle $(\boldsymbol{\Delta} P<0.005)$. Data represent the average of three independent experiments $(n=3)$; bars, mean \pm SEM not directly block the access of ligand to the receptor. Table 2 also lists the dimer interface residues. Indeed, the interface residues do not share common elements with the SSZ/NADPH+ binding pocket. Only Tyr167, which is part of both ligand sites, is found in the vicinity of an interface residue, i.e. Cys168.

Figure 5 shows the binding of SSZ to SPR monomer and dimer, respectively. Both chains were found to simultaneously bind ligands in the dimer. While the SSZ site is close to the $\mathrm{N}$-terminus in the primary structure, it appears near the middle of the protein in the $3 \mathrm{D}$ fold. The binding pocket is not in very close contact with the dimerization interface and only a few side chains project into the joint neighborhood. The figure also shows the $\mathrm{NADP}+$ binding site of SPR in side-by-side comparison and overlay mode with SSZ. The superimposition of the ligands clearly illustrates that the two binding sites are essentially the same. The geometric center of SSZ and NADP+ is separated only by about $0.5 \AA$ from each other in the superimposed binding pockets. Thus, from Fig. 5 and Table 2 it appears that the binding site for SSZ coincides with the region previously identified in NADP+ binding in the X-ray structure. As a consequence, this could help elucidate the interaction between SSZ and SPR in in vitro and in vivo studies.

\section{Synergism of SSZ and DFMO combination treatment in NB cells}

To test whether the combined treatment with SSZ and DFMO induces synergistic cell death in NB, we treated 
Table 2 Amino acid residues at the binding sites of SPR-SSZ, SPR-NADP+, and SPR-SPR complexes

\begin{tabular}{|c|c|c|}
\hline SSZ & NADP+ & SPR Dimer \\
\hline Pocket & Pocket & Interface \\
\hline Gly11 & Gly11 & - \\
\hline Ser13 & Ser13 & - \\
\hline \multirow[t]{2}{*}{ Arg14 } & Arg14 & - \\
\hline & Gly15 & - \\
\hline Phe16 & Phe16 & - \\
\hline Ala38 & - & - \\
\hline Arg39 & Arg39 & - \\
\hline- & Asn40 & - \\
\hline- & Ala65 & - \\
\hline- & Asp66 & - \\
\hline- & Leu67 & - \\
\hline- & - & Glu70 \\
\hline Asn97 & Asn97 & - \\
\hline Ala98 & - & - \\
\hline Gly99 & - & - \\
\hline Ser100 & - & - \\
\hline- & - & Gly107 \\
\hline- & - & Phe108 \\
\hline- & - & Val109 \\
\hline- & - & Asp110 \\
\hline- & - & Leu111 \\
\hline- & - & Ser114 \\
\hline- & - & Val117 \\
\hline- & - & Asn118 \\
\hline - & - & Trp121 \\
\hline- & - & Ala122 \\
\hline - & Leu123 & - \\
\hline - & - & Thr126 \\
\hline- & - & Leu129 \\
\hline - & - & Ser133 \\
\hline- & - & Lys137 \\
\hline- & Ile152 & - \\
\hline - & Ser153 & - \\
\hline- & - & Pro160 \\
\hline - & - & Phe161 \\
\hline- & - & Lys162 \\
\hline- & - & Gly163 \\
\hline- & - & Ala165 \\
\hline Tyr167 & Tyr167 & - \\
\hline - & - & Cys 168 \\
\hline- & - & Ala169 \\
\hline- & Lys171 & - \\
\hline
\end{tabular}

Table 2 Amino acid residues at the binding sites of SPR-SSZ, SPR-NADP+, and SPR-SPR complexes (Continued)

\begin{tabular}{lll}
\hline- & - & Ala173 \\
- & - & Met176 \\
- & - & Leu177 \\
- & - & Val180 \\
- & - & Leu181 \\
- & - & Leu183 \\
- & - & Glu184 \\
- & Pro195 & - \\
- & Gly196 & - \\
- & Pro197 & - \\
Leu198 & Leu198 & - \\
Thr200 & Thr200 & - \\
Met202 & Met202 & - \\
- & Gln203 & - \\
\hline Cutoff distance: 3.6 Angstrom & &
\end{tabular}

SK-N-Be(2)c and LAN-5 cells with different concentrations of SSZ and DFMO. We used two common methods to analyze drug-drug interactions, the isobologram and the combination index $(\mathrm{CI})$ analysis. For both combination analyses, we measured the SSZ and DFMO interaction at $50 \%$ effect level. We first determined the singleagent $\mathrm{IC}_{50}$ concentration for SSZ and DFMO in NB cell lines SK-N-Be(2)c and LAN-5 (Fig. 6, a and b) using an MTS cell viability assay after $48 \mathrm{~h}$ of treatment. SSZ exhibited an $\mathrm{IC}_{50}$ value of $133.1 \mu \mathrm{M}$ for SK-N-Be(2)c and $337.2 \mu \mathrm{M}$ for LAN-5 cells. DFMO showed an $\mathrm{IC}_{50}$ value of $4.07 \mathrm{mM}$ for SK-N-Be(2)c and $5.79 \mathrm{mM}$ for LAN-5 cells. Subsequently, we combined SSZ and DFMO at different concentrations based on each $\mathrm{IC}_{50}$ value to treat the two NB cell lines, generated isobolograms, and calculated the $\mathrm{CI}$ values illustrating the observed synergy. As shown in Fig. 6c and Table 3, SSZ and DFMO combinations revealed slight synergism in SK-N-Be(2)c cells when drug concentrations were below $29.64 \mu \mathrm{M}$ and $1.80 \mathrm{mM}$, respectively. Strikingly, SSZ and DFMO showed strong synergism in LAN-5 cells when drug concentrations were below $1.20 \mu \mathrm{M}$ and $1.21 \mathrm{mM}$, respectively.

\section{Discussion}

SSZ is a salicylate-based anti-inflammatory drug; one of the most important medicines used worldwide in basic health care according to the WHO Model List of Essential Medicines (http://www.who.int/medicines/publications/essentialmedicines/en/). Its mode of action involves the anti-inflammatory and immune-modulatory properties of its metabolic constituent, 5-aminosalicylic acid $[31,36]$. SSZ is most commonly used to treat bowel inflammation, diarrhea, rectal bleeding, and abdominal 
a

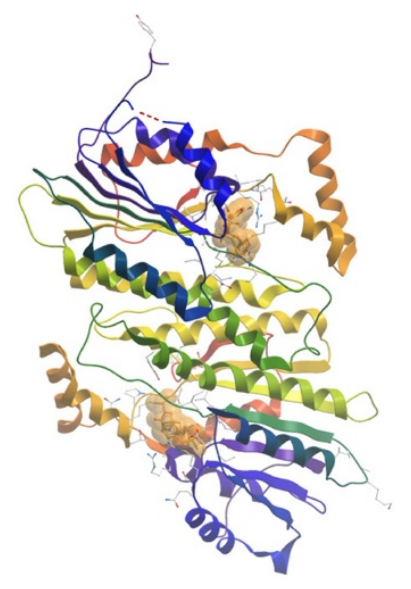

C

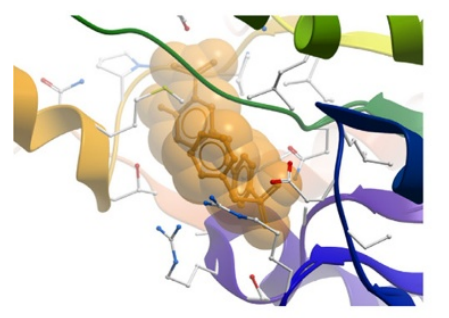

e

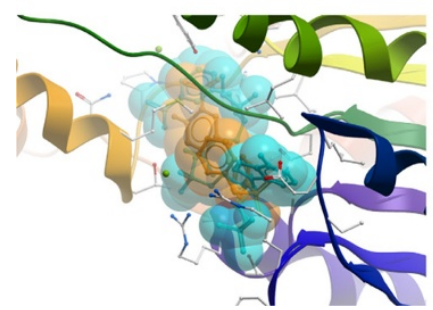

b

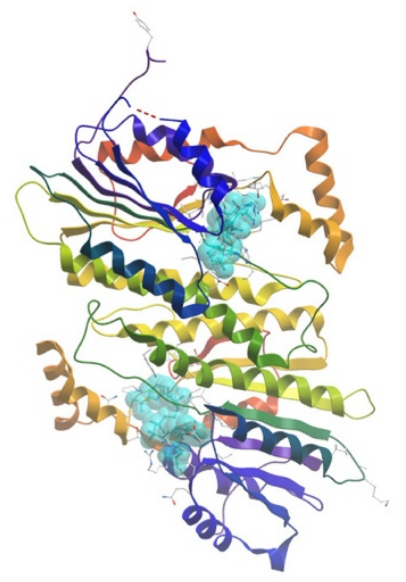

d

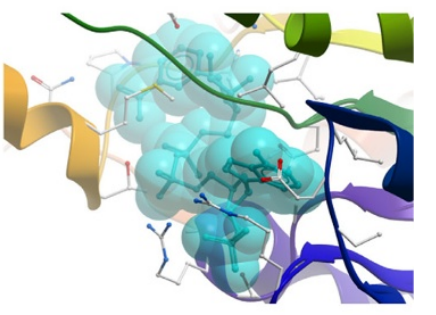

Fig. 5 Binding of SSZ to SPR. (a) SPR dimer front view (C2 axis). Both chains bind SSZ independently. (b) SPR dimer in complex with NADP+. (c) SPR monomer close-up front view of the SSZ binding pocket: (d) SPR monomer close-up front view of the NADP+ binding pocket. (e) Overlay view of SSZ and NADP+ binding sites. The two binding sites overlap upon 3D alignment of the SPR protein chains. The amino acid residues involved in SSZ and NADP binding are listed in Table 2. Color scheme for the molecular constituents: Protein chain ribbon - rainbow spectrum from N-terminus (blue) to C-terminus (red); SSZ space fill - amber; NADP+ spacefill - cyan

pain in patients with ulcerative colitis. So far, nothing is known about a potential therapeutic effect of SSZ in NB.

Molecular and computational studies presented in this work and in [32] suggest that the SSZ target molecule SPR may constitute a novel druggable protein in NB. Both chains of the SPR homodimer were found to simultaneously bind ligands in the docking simulations and the SSZ binding site was located at the NADP-binding Rossmann fold. Thus, competition between SSZ and $\mathrm{NADP}+$ may modulate or inhibit the activity of SPR as the two ligands do not have an equivalent enzymatic role. In addition to occupying the same receptor pocket, complex formation with SSZ could locally perturb the dimerization interface. Binding region 4 includes the aromatic residue Tyr 167 that is situated near the dimer interface in a relatively apolar area and may affect the thermodynamics of ligand and inhibitor binding as well as the protein dimerization. It remains to be clarified in further work whether the primary physiological role of SSZ is competitive/non-competitive inhibition or perturbation of dimerization which would in turn disrupt the functional biological unit in addition to the enzymatic changes.

\section{Conclusions}

The results of the NB cell experiments show that SSZ has a detrimental effect on NB cells in in vitro culture and shows synergy with DFMO treatment which is encouraging. The identification of the molecular pathways that are activated in response to SSZ action will need further studies. Considering the low toxicity of DFMO and its current use in NB clinical trials [26-28], a combination with the equally low toxic and clinically evaluated SSZ appears a good lead for future clinical studies. 

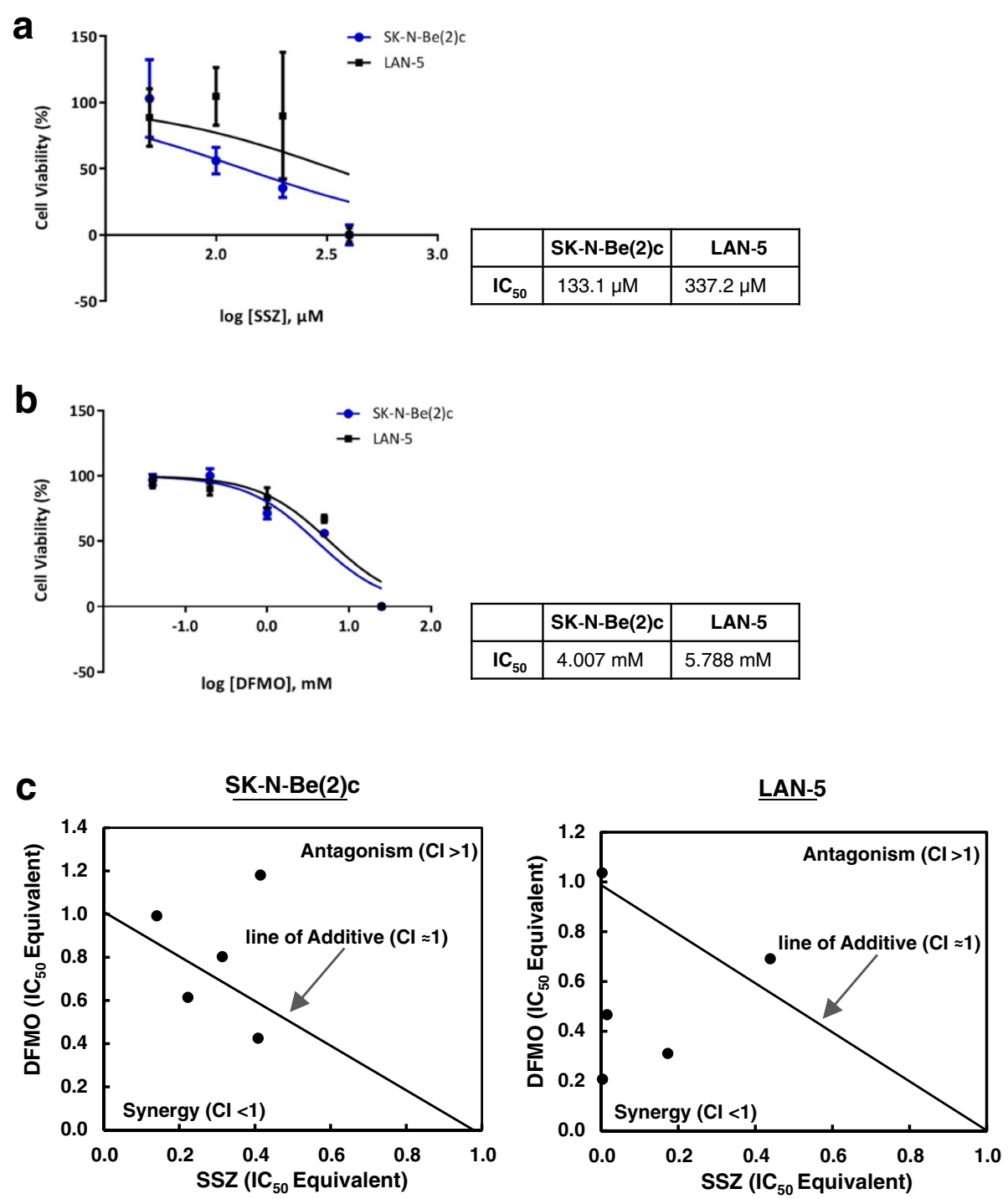

Fig. 6 Isobologram analysis for SSZ and DFMO in NB. Isobolograms were prepared to determine synergisms between SSZ and DFMO. NB cell lines SK-N-Be(2)c and LAN-5 were used to determine the inhibitory concentration at which $50 \%$ of cells are dead $\left(\mathrm{IC}_{50}\right)$ after $48 \mathrm{~h}$ of treatment with (a) SSZ

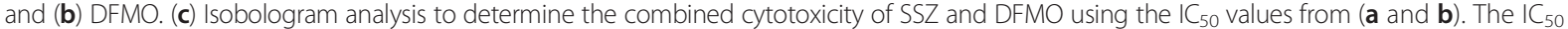
value of SSZ and DFMO used in combination provides the connective points for the line of additive. Synergy, additivity, or antagonism is indicated below, on, or above the line, respectively. The data present the average of three independent experiments in duplicate $(n=6)$; points, mean \pm SEM

\section{Methods}

\section{Mammalian cell culture and reagents}

The human NB cell line SK-N-Be(2)c was obtained from Dr. Giselle Sholler (Helen DeVos Children's Hospital, Grand Rapids, MI). The human NB cell line LAN-5 was obtained from Dr. Randal Wada (John A. Burns School of Medicine, University of Hawaii at Manoa, Honolulu, $\mathrm{HI}$ ). The human NB cell line SK-N-SH was purchased from the American Type Culture Collection (Manassas, VA). Cells were maintained in RPMI 1640 media (Mediatech Inc, Manassas, VA) containing $10 \%$ heatinactivated fetal bovine serum (FBS) (Atlanta Biologicals,
Inc, Lawrenceville, GA), penicillin (100 IU/mL), and streptomycin (100 Ag/mL) (Mediatech). Sulfasalazine (SSZ) (Santa Cruz Biotechnology, Inc, Dallas, TX) stock solution was prepared at $250 \mathrm{mM}$ concentration in dimethyl sulfoxide (DMSO) (Electron Microscopy Sciences, Hatfield, PA). DFMO was a kind gift of Dr. Patrick Woster (Medical University of South Carolina, Charleston, SC) and dissolved in water to make a stock solution of $250 \mathrm{mM}$ as previously reported [18, 19, 21]. SSZ and DFMO were diluted with culture medium before treating the cells. An equal concentration of DMSO was used for control treatments. 
Table 3 Combination treatment of SSZ and DFMO in SK-N$\mathrm{Be}(2) \mathrm{C}$ and LAN-5 cells for $48 \mathrm{~h}$

\begin{tabular}{|c|c|c|c|c|c|c|}
\hline \multirow[b]{2}{*}{$\begin{array}{l}\text { NB Cell } \\
\text { Line }\end{array}$} & \multicolumn{2}{|c|}{$\begin{array}{l}\text { Concentration, } \\
I_{50} \text { Equivalent }\end{array}$} & \multirow[b]{2}{*}{$\begin{array}{l}\text { Combination } \\
\text { Index at } 50 \% \\
\text { Effect Level }\end{array}$} & \multirow[b]{2}{*}{$\begin{array}{l}\text { Evaluation } \\
\text { at } 50 \% \\
\text { Effect Level }\end{array}$} & \multirow[b]{2}{*}{$\begin{array}{l}\mathrm{SSZ} I \mathrm{C}_{50} \\
(\mu \mathrm{M})\end{array}$} & \multirow[b]{2}{*}{$\begin{array}{l}\text { DFMO } \\
(\mathrm{mM})\end{array}$} \\
\hline & SSZ & DFMO & & & & \\
\hline \multirow[t]{5}{*}{$\begin{array}{l}\text { SK-N- } \\
\operatorname{Be}(2) c\end{array}$} & 0.408 & 0.425 & 0.834 & $\begin{array}{c}\text { slight } \\
\text { synergism }\end{array}$ & 54.360 & 1.800 \\
\hline & 0.223 & 0.614 & 0.837 & $\begin{array}{l}\text { slight } \\
\text { synergism }\end{array}$ & 29.640 & 2.600 \\
\hline & 0.314 & 0.803 & 1.117 & $\begin{array}{l}\text { moderate } \\
\text { antagonism }\end{array}$ & 41.740 & 3.400 \\
\hline & 0.140 & 0.992 & 1.132 & $\begin{array}{c}\text { moderate } \\
\text { antagonism }\end{array}$ & 18.700 & 4.200 \\
\hline & 0.415 & 1.181 & 1.595 & antagonism & 55.180 & 5.000 \\
\hline \multirow[t]{5}{*}{ LAN-5 } & 0.004 & 0.207 & 0.211 & $\begin{array}{c}\text { strong } \\
\text { synergism }\end{array}$ & 1.207 & 1.200 \\
\hline & 0.173 & 0.311 & 0.484 & synergism & 58.250 & 1.800 \\
\hline & 0.015 & 0.466 & 0.482 & synergism & 5.152 & 2.700 \\
\hline & 0.439 & 0.691 & 1.130 & $\begin{array}{c}\text { moderate } \\
\text { antagonism }\end{array}$ & 147.900 & 4.000 \\
\hline & 0.003 & 1.037 & 1.039 & additive & 0.893 & 6.000 \\
\hline
\end{tabular}

Legend: The concentration in $\mathrm{IC}_{50}$ equivalent of SSZ was calculated by dividing the $I_{50}$ of SSZ with DFMO combination from its corresponding single-agent $I C_{50}$ value $\left(\mathrm{IC}_{50}\right.$ of SSZ w/ DFMO comb/SSZ IC $\left.\mathrm{C}_{50}\right)$. For DFMO, the concentration in $\mathrm{IC}_{50}$ equivalent was calculated by dividing its actual concentration used in the combination treatment from its corresponding single-agent $\mathrm{IC}_{50}$ value (DFMO/ DFMO $\left(\mathrm{C}_{50}\right)$. Combination index $(\mathrm{Cl})$ at $50 \%$ effect level is calculated by adding the $\mathrm{IC}_{50}$ equivalent concentration of SSZ and DFMO. $\mathrm{Cl}>1.3$ is antagonism; $\mathrm{Cl}=$ 1.1-1.3 is moderate antagonism; $\mathrm{Cl}=0.9-1.1$ is additive; $\mathrm{Cl}=0.8-0.9$ is slight synergism; $\mathrm{Cl}=0.6-0.8$ is moderate synergism; $\mathrm{Cl}=0.4-0.6$ is synergism; $\mathrm{Cl}=0.2-0.4$ is strong synergism. Synergism was detected at two different combinations of DFMO and SSZ in SK-N-Be(2)c cells and three different combinations in LAN-5 cells (bold italics). The data present the average of three independent experiments performed in duplicate $(\mathrm{n}=6)$

\section{Cell viability assay}

Prior to treatment, cells were cultured overnight in 96-well microtiter plates (Greiner Bio-One Inc, Monroe, NC). LAN-5, SK-N-Be(2)c, or SK-N-SH cells were seeded at concentrations of $1.5,5.0$, or $1.0 \times 10^{4}$ cells per well, respectively. All NB cell lines were suspended in $90 \mu \mathrm{l}$ of medium per well. After overnight incubation, NB cells were treated with increasing concentrations of SSZ $(0-400 \mu \mathrm{M})$ or DFMO (0-25 mM) for $48 \mathrm{~h}$. An equal concentration of DMSO was used as a control. Cell viability was measured with the CellTiter 96 AQueous One Solution Cell Proliferation Assay (MTS Assay) (Promega BioSciences, San Luis Obispo, CA) following the manufacturer's protocol. Briefly, $20 \mu \mathrm{L}$ of CellTiter 96 AQueous One Solution Reagent was added to each well and incubated at $37{ }^{\circ} \mathrm{C}$ for $3 \mathrm{~h}$. The quantity of formazan product that is proportional to the number of living cells in the culture was measured at $490 \mathrm{~nm}$ using the Synergy Mx Monochromator-Based Multi-Mode Microplate Reader (BioTek Instruments, Inc, Winooski, VT). Optical density (OD) readings were calculated and evaluated using Excel spreadsheet software (Microsoft, Redmund, WA).

\section{Isobologram and combination index analyses}

Isobologram and combination index (CI) analyses were performed as previously described [37-40] with some modifications. Isobologram analysis is a graphical presentation of the interaction of two drugs at a chosen effect level, such as $50 \%$ effect level or $\mathrm{IC}_{50}$ equivalent concentration. CI analysis is used to quantitatively measure the interaction of two drugs at a chosen effect level. In this study, the $50 \%$ effect level was used for both analyses. The $\mathrm{IC}_{50}$ values of SSZ and DFMO for SK-N-Be(2)c and LAN-5 NB cell lines were calculated using the nonlinear log inhibitor versus normalized response curve fit function from GraphPad Prism 6 software (La Jolla, CA). Based on this single-agent $\mathrm{IC}_{50}$ determination, each $\mathrm{NB}$ cell line was treated with a combination of SSZ and DFMO at different concentrations. Seven different concentrations of SSZ ranging from $2.34 \mu \mathrm{M}$ to $150 \mu \mathrm{M}$, and $5.47 \mu \mathrm{M}$ to $350 \mu \mathrm{M}$ were used to treat SK-N-Be(2)c and LAN-5 cells, respectively. Five different concentrations of DFMO ranging from $1.8 \mathrm{mM}$ to $5.0 \mathrm{mM}$, and $1.2 \mathrm{mM}$ to $6.0 \mathrm{mM}$ were used to treat SK-N-Be(2)c and LAN-5, respectively. The CellTiter 96 AQueous One Solution Cell Proliferation Assay (Promega) was used to measure the drug activity for each NB cell line. Excel spreadsheet software and GraphPad Prism 6 software were used to plot the isobologram and determined the CI for each NB cell line combination treatment. The line of additivity on the isobologram represents the $50 \%$ effect level of each drug.

\section{Protein-ligand docking}

Atomic coordinates from X-ray crystal structures of human sepiapterin reductase (SPR; PDB:1Z6Z) were obtained from the Protein Data Bank [41] and used for molecular docking. The crystallographic assembly is a homo 6-mer (A6) and the single repeating unit consists of residues $\mathrm{L}(-) 5$ to $\mathrm{K} 258$. The protein chain is in complex with NADP+. The quaternary structure of the biological unit is a homo 2-mer (A2).

Sulfasalazine (Compound ID: 5384001/5359476) structure information was retrieved from the PubChem Substance and Compound Database [35]. Three-dimensional coordinates were available for a stable conformer, energy minimized by the MMFF94 force field [33].

Molecular docking was carried out to locate plausible SSZ binding sites in SPR. The Global Range Molecular Matching method (GRAMM) was employed on local computers in high-resolution geometric docking modes using both a long-distance-potentials approach [42] and correlation techniques [43]. The GRAMM algorithm identifies the docking areas by computing the intermolecular energy potential in protein-ligand complexes through a 
comprehensive multidimensional search of relative molecular positions and orientations. A low-resolution semiflexible mode was also used to account for conformational flexibility $[44,45]$.

The docking simulations were run with SPR monomers and dimers, each in complex with the energy-minimized SSZ conformer. The first 50 binding locations of every run were scored by the binding energy between the ligand and the protein and by the presence or absence of amino acid residues in the contact surfaces among the various protein-ligand pairs. The complexes with the lowest spatial variations were chosen as the most plausible models. The predicted binding sites were visualized with the ICMBrowser (Molsoft, San Diego, CA). The ICM Molecular Editor (Molsoft) was used for chemical structure drawing.

\section{NB public mRNA expression dataset analysis}

Human NB mRNA expression datasets in the public domain were analyzed using R2: a genomics analysis and visualization platform developed in the Department of Oncogenomics at the Academic Medical Center - University of Amsterdam (http://r2.amc.nl). Expression data (CEL files) for the datasets were retrieved from the public Gene Expression Omnibus (GEO) dataset on the NCBI website (http://www.ncbi.nlm.nih.gov/geo/). All analysis of human material and human data was in compliance with the "Declaration of Helsinki for Medical Research involving Human Subjects" (http://www.wma.net/en/30publications/10policies/b3/index.html). In addition, approval was obtained from the "Medisch Ethische Commissie (MEC) van het AMC (Amsterdam)", the local research and ethics committee. CEL data were analyzed as described in [46]. Briefly, gene transcript levels were determined from data image files using GeneChip operating software (MAS5.0 and GCOS1.0, from Affymetrix). Samples were scaled by setting the average intensity of the middle $96 \%$ of all probe-set signals to a fixed value of 100 for every sample in the dataset, allowing comparisons between micro-arrays. The TranscriptView genomic analysis and visualization tool within R2 was used to check if probe-sets had an anti-sense position in an exon of the gene (http://r2.amc.nl > genome browser). The probe-sets selected for SPR (Affymetrix 203458_at and Illumina 1705849) and ODC1 (Affymetrix 200790_at and Illumina 1748591) meet these criteria. All expression values and other details for the datasets used can be obtained through their GSE number from the NCBI GEO website.

\section{Statistical analysis}

SPR mRNA expression and correlation with important NB clinical parameters were determined using the nonparametric Kruskal-Wallis test; correlation with ODC mRNA expression was calculated with a $2 \log$ Pearson test. The significance of a correlation is determined by
$\mathrm{t}=\mathrm{R} / \mathrm{sqrt}\left(\left(1-\mathrm{r}^{\wedge} 2\right) /(\mathrm{n}-2)\right)$, where $\mathrm{R}$ is the correlation value and $\mathrm{n}$ is the number of samples. Distribution measure is approximately as $\mathrm{t}$ with $\mathrm{n}-2^{\circ}$ of freedom. For all tests, $P$ $<0.05$ was considered statistically significant. The statistical significance of SSZ treatments in cell viability experiments was determined by Microsoft Excel's Student's paired $t$-Test, with one-tailed distributions.

\section{Abbreviations}

DFMO: alpha-difluoromethylornithine; NADP: Nicotinamide adenine dinucleotide phosphate; SPR: Sepiapterin reductase; SSZ: Sulfasalazine.

\section{Competing interests}

The authors declare that they have no competing interest exists.

\section{Authors' contribution}

LPY performed cell proliferation, Western blotting experiments, and isobologram analysis. DG received funds and analyzed the clinical tumor data with SPR in NB tumors. GM performed the molecular docking with ligand. JK performed the statistical analyses. ASB conceived the project, received funds, and contributed intellectually toward the design of this study, supervised LPY, and wrote most of the manuscript. All authors participated in writing the manuscript and approved the final submission.

\section{Acknowledgements}

We thank Dr. Giselle Sholler (Helen DeVos Children's Hospital, Grand Rapids, MI) for providing NB cell line SK-N-Be(2)c and Dr. Randal Wada (University of Hawaii at Manoa, Honolulu, HI) for NB cell line LAN-5. Dr. Patrick Woster (Medical University of South Carolina, Charleston, SC) is thanked for providing DFMO. This work was supported by the Ingeborg v.F. McKee Fund and Tai Up Yang Fund of the Hawaii Community Foundation (HCF) grant 14ADVC-64573 (André S. Bachmann), the Daniel K. Inouye College of Pharmacy internal funds (André S. Bachmann), the Dutch Cancer Society ("KWF Kankerbestrijding") UVA2005-3665 (Dirk Geerts), and the European Union COST Action BM0805 (Dirk Geerts).

\section{Author details}

'Department of Pediatrics and Human Development, College of Human Medicine, Michigan State University, 301 Michigan Street, NE, Grand Rapids, MI 49503, USA. ${ }^{2}$ Department of Pharmaceutical Sciences, The Daniel K. Inouye College of Pharmacy, University of Hawaii at Hilo, Hilo, HI 96720, USA. ${ }^{3}$ Department of Molecular Biosciences and Bioengineering, College of Tropical Agriculture and Human Resources, University of Hawaii at Manoa, Honolulu, HI 96822, USA. ${ }^{4}$ Department of Pediatric Oncology/Hematology, Sophia Children's Hospital, Erasmus University Medical Center, Rotterdam, GE 3015, The Netherlands. ${ }^{5}$ Pacific Biosciences Research Center, University of Hawaii at Manoa, Honolulu, HI 96822, USA. 'Department of Oncogenomics, Academic Medical Center, University of Amsterdam, Amsterdam, AZ 1105, The Netherlands.

Received: 5 March 2015 Accepted: 19 May 2015

Published online: 21 June 2015

\section{References}

1. Brodeur GM. Neuroblastoma: biological insights into a clinical enigma. Nat Rev Cancer. 2003;3(3):203-16.

2. Cheung NK, Dyer MA. Neuroblastoma: developmental biology, cancer genomics and immunotherapy. Nat Rev Cancer. 2013;13(6):397-411.

3. Maris JM. Recent advances in neuroblastoma. N Engl J Med. 2010;362(23):2202-11.

4. Maris JM, Hogarty MD, Bagatell R, Cohn SL. Neuroblastoma. Lancet. 2007;369(9579):2106-20.

5. Park JR, Eggert A, Caron H. Neuroblastoma: biology, prognosis, and treatment. Hematol Oncol Clin North Am. 2010;24(1):65-86.

6. Schwab M, Westermann F, Hero B, Berthold F. Neuroblastoma: biology and molecular and chromosomal pathology. Lancet Oncol. 2003;4(8):472-80.

7. Baker DL, Schmidt ML, Cohn SL, Maris JM, London WB, Buxton A, et al. Outcome after reduced chemotherapy for intermediate-risk neuroblastoma. N Engl J Med. 2010;363(14):1313-23. 
8. Cohn SL, Pearson AD, London WB, Monclair T, Ambros PF, Brodeur GM, et al. The International Neuroblastoma Risk Group (INRG) classification system: an INRG Task Force report. J Clin Oncol. 2009;27(2):289-97.

9. Kreissman SG, Seeger RC, Matthay KK, London WB, Sposto R, Grupp SA et al. Purged versus non-purged peripheral blood stem-cell transplantation for high-risk neuroblastoma (COG A3973): a randomised phase 3 trial. Lancet Oncol. 2013;14(10):999-1008.

10. Strother DR, London WB, Schmidt ML, Brodeur GM, Shimada H, Thorner P, et al. Outcome after surgery alone or with restricted use of chemotherapy for patients with low-risk neuroblastoma: results of Children's Oncology Group study P9641. J Clin Oncol. 2012;30(15):1842-8.

11. Canete A, Gerrard M, Rubie H, Castel V, Di Cataldo A, Munzer C, et al. Poor survival for infants with MYCN-amplified metastatic neuroblastoma despite intensified treatment: the International Society of Paediatric Oncology European Neuroblastoma Experience. J Clin Oncol. 2009;27(7):1014-9.

12. Kushner BH, Kramer K, LaQuaglia MP, Modak S, Yataghene K, Cheung NK. Reduction from seven to five cycles of intensive induction chemotherapy in children with high-risk neuroblastoma. J Clin Oncol. 2004:22(24):4888-92

13. Bachmann AS. The role of polyamines in human cancer: prospects for drug combination therapies. Hawaii Med J. 2004;63(12):371-4.

14. Casero Jr RA, Marton LJ. Targeting polyamine metabolism and function in cancer and other hyperproliferative diseases. Nat Rev Drug Discov. 2007;6(5):373-90.

15. Pegg AE. Polyamine metabolism and its importance in neoplastic growth and a target for chemotherapy. Cancer Res. 1988;48(4):759-74.

16. Pegg AE, Feith DJ. Polyamines and neoplastic growth. Biochem Soc Trans. 2007;35(Pt 2):295-9.

17. Gerner EW, Meyskens Jr FL. Polyamines and cancer: old molecules, new understanding. Nat Rev Cancer. 2004:4(10):781-92.

18. Koomoa DL, YCO LP, Borsics T, Wallick CJ, Bachmann AS. Ornithine decarboxylase inhibition by \{alpha\}-difluoromethylornithine activates opposing signaling pathways via phosphorylation of both Akt/Protein Kinase B and p27Kip1 in neuroblastoma. Cancer Res. 2008:68(23):9825-31.

19. Wallick CJ, Gamper I, Thorne M, Feith DJ, Takasaki KY, Wilson SM, et al. Key role for p27Kip1, retinoblastoma protein $\mathrm{Rb}$, and MYCN in polyamine inhibitor-induced G1 cell cycle arrest in MYCN-amplified human neuroblastoma cells. Oncogene. 2005:24(36):5606-18.

20. Koomoa DL, Borsics T, Feith DJ, Coleman CC, Wallick CJ, Gamper I, et al. Inhibition of S-adenosylmethionine decarboxylase by inhibitor SAM486A connects polyamine metabolism with p53-Mdm2-Akt/protein kinase B regulation and apoptosis in neuroblastoma. Mol Cancer Ther. 2009:8(7):2067-75.

21. Koomoa DL, Geerts D, Lange I, Koster J, Pegg AE, Feith DJ, et al. DFMO/ eflornithine inhibits migration and invasion downstream of MYCN and involves p27Kip1 activity in neuroblastoma. Int J Oncol. 2013:42(4):1219-28.

22. Bandino A, Geerts D, Koster J, Bachmann AS. Deoxyhypusine synthase (DHPS) inhibitor GC7 induces p21/Rb-mediated inhibition of tumor cell growth and DHPS expression correlates with poor prognosis in neuroblastoma patients. Cell Oncol. 2014;37(6):387-98.

23. Hogarty MD, Norris MD, Davis K, Liu X, Evageliou NF, Hayes CS, et al. ODC1 Is a Critical Determinant of MYCN Oncogenesis and a Therapeutic Target in Neuroblastoma. Cancer Res. 2008;68(23):9735-45.

24. Rounbehler RJ, Li W, Hall MA, Yang C, Fallahi M, Cleveland JL. Targeting ornithine decarboxylase impairs development of MYCN-amplified neuroblastoma. Cancer Res. 2009:69(2):547-53.

25. Sholler G, Currier E, Koomoa DL, Bachmann AS. Synergistic inhibition of neuroblastoma tumor development by targeting ornithine decarboxylase and topoisomerase II. In: 14th Advances in Neuroblastoma Research (ANR) Conference. Stockholm, Sweden, June 21-24; 2010: POT74.

26. Saulnier Sholler GL, Gerner EW, Bergendahl G, MacArthur MW, VanderWerff A, Ashikaga T, Bond JP, Ferguson W, Roberts W, Wada RK et al:: A phase I trial of DFMO targeting polyamine addiction in patients with relapsed/ refractory neuroblastoma. PloS One 2015, In Press.

27. Bachmann AS, Geerts D, Sholler G: Neuroblastoma: Ornithine decarboxylase and polyamines are novel targets for therapeutic intervention. In: Pediatric Cancer, Neuroblastoma: Diagnosis, Therapy, and Prognosis. Volume 1, edn. Edited by Hayat MA: Springer, Heidelberg, Germany. 2012;91-103.

28. Bachmann AS, Levin VA. Clinical applications of polyamine-based therapeutics. In: Polyamine Drug Discovery. edn. Edited by Woster PM, Casero RA, Jr.: Royal Society of Chemistry Publishing, Cambridge, UK. 2012;257-276.
29. Samal K, Zhao P, Kendzicky A, Yco LP, McClung H, Gerner E, et al. AMXT-1501, a novel polyamine transport inhibitor, synergizes with DFMO in inhibiting neuroblastoma cell proliferation by targeting both ornithine decarboxylase and polyamine transport. Int J Cancer. 2013;133(6):1323-33.

30. Chidley C, Haruki H, Pedersen MG, Muller E, Johnsson K. A yeast-based screen reveals that sulfasalazine inhibits tetrahydrobiopterin biosynthesis. Nat Chem Biol. $2011 ; 7(6): 375-83$.

31. Costigan M, Latremoliere A, Woolf CJ. Analgesia by inhibiting tetrahydrobiopterin synthesis. Curr Opin Pharmacol. 2012;12(1):92-9.

32. Lange I, Geerts D, Feith DJ, Mocz G, Koster J, Bachmann AS. Novel interaction of ornithine decarboxylase with sepiapterin reductase regulates neuroblastoma cell proliferation. J Mol Biol. 2014;426(2):332-46.

33. Halgren TA. Merck molecular force field. I. Basis, form, scope, parameterization, and performance of MMFF94. J Comp Chem. 1996;17(5/6):490-519.

34. Sillitoe I, Cuff AL, Dessailly BH, Dawson NL, Furnham N, Lee D, et al. New functional families (FunFams) in CATH to improve the mapping of conserved functional sites to 3D structures. Nucleic Acids Res. 2013:41(Database issue):D490-498.

35. Bolton EE, Chen J, Kim S, Han L, He S, Shi W, et al. PubChem3D: a new resource for scientists. Journal of cheminformatics. 2011;3(1):32.

36. van Rossum MA, Fiselier TJ, Franssen MJ, Zwinderman AH, ten Cate R, van Suijlekom-Smit LW, et al. Sulfasalazine in the treatment of juvenile chronic arthritis: a randomized, double-blind, placebo-controlled, multicenter study. Dutch Juvenile Chronic Arthritis Study Group. Arthritis Rheum. 1998;41(5):808-16

37. Berenbaum MC. What is synergy? Pharmacol Rev. 1989:41(2):93-141.

38. Zhao L, Au JL, Wientjes MG. Comparison of methods for evaluating drug-drug interaction. Front Biosci. 2010;2:241-9.

39. Chou TC. Theoretical basis, experimental design, and computerized simulation of synergism and antagonism in drug combination studies. Pharmacol Rev. 2006;58(3):621-81.

40. Chou TC. Drug combination studies and their synergy quantification using the Chou-Talalay method. Cancer Res. 2010;70(2):440-6.

41. Berman HM, Battistuz T, Bhat TN, Bluhm WF, Bourne PE, Burkhardt $K$, et al. The Protein Data Bank. Acta Crystallogr D Biol Crystallogr. 2002:58(Pt 6 No 1):899-907.

42. Vakser IA. Long-distance potentials: an approach to the multiple-minima problem in ligand-receptor interaction. Protein Eng. 1996;9(1):37-41.

43. Katchalski-Katzir E, Shariv I, Eisenstein M, Friesem AA, Aflalo C, Vakser IA. Molecular surface recognition: determination of geometric fit between proteins and their ligands by correlation techniques. Proc Natl Acad Sci U S A. 1992:89(6):2195-9.

44. Vakser IA. Protein docking for low-resolution structures. Protein Eng 1995:8(4):371-7.

45. Vakser IA. Low-resolution docking: prediction of complexes for underdetermined structures. Biopolymers. 1996;39(3):455-64.

46. Revet I, Huizenga G, Chan A, Koster J, Volckmann R, van Sluis P, et al. The MSX1 homeobox transcription factor is a downstream target of PHOX2B and activates the Delta-Notch pathway in neuroblastoma. Exp Cell Res. 2008:314(4):707-19.

\section{Submit your next manuscript to BioMed Central and take full advantage of:}

- Convenient online submission

- Thorough peer review

- No space constraints or color figure charges

- Immediate publication on acceptance

- Inclusion in PubMed, CAS, Scopus and Google Scholar

- Research which is freely available for redistribution 